\title{
Rituximab reduces the hospitalization in patients with systemic lupus erythematosus
}

\author{
R Martínez-Pérez ${ }^{1 *}$, A Fernández-Nebro² ${ }^{2}$ M López-Lasanta² ${ }^{2}$ M L Velloso-Feijoo ${ }^{1}$, A Muñoz-Jiménez ${ }^{1}$, \\ J López Longo ${ }^{3}$, J L Marenco ${ }^{1}$ \\ From 5th European Workshop on Immune-Mediated Inflammatory Diseases \\ Sitges-Barcelona, Spain. 1-3 December 2010
}

\section{Introduction}

Systemic Lupus Erythematosus (SLE) is a chronic inflammatory disease of unknown etiology. The evolution of the disease is unpredictable. Most patients follow a chronic course and have flare-ups or exacerbations, with a number of hospital admissions.

\section{Hypothesis and objectives}

The use of Rituximab (RTX) decrease the hospital admissions in SLE patients refractory to immunosuppressive therapy.

\section{Material and methods}

This is an observational, retrospective and multicenter study. Sequential observation was made at baseline, at $24^{\text {th }}$ week and final visit. The outcome variables were: clinic improvement measured by SLEDAI, Physician's Global Assessment (PGA) and patient hospitalization for SLE during the $24^{\text {th }}$ week and final visit. Statistical analysis of the qualitative and quantitative variables was done by Chi-square and T-test/Wolcoxon, respectively.

\section{Results}

We treated 46 patients (94\% women), mean age $36.50 \pm$ 11.47 ages, 91\% Caucasians.

Monitoring: mean of $21,1 \pm 13,9$ months. The main reason for use of RTX was: nephritis (24\%,) arthritis (28\%), thrombocytopenia (11\%), neurological (13\%), cutaneous $(13 \%)$ and others (11\%).

The most common dose used was $2 x 1 \mathrm{~g}(87 \%)$. The median of cycles was 2 (rank 1-3). Patients treated with RTX improved SLEDAI, PGA and reduced hospital admissions (table 1).
Table 1 Endpoints

\begin{tabular}{llll}
\hline & Baseline & 24th week & Final Visit \\
\hline $\begin{array}{l}\text { SLEDAI (0-105), median } \\
\text { (rank) }\end{array}$ & $14.5(7.8-22.3)$ & $4.0(2.0-6.0)^{* *}$ & $2.0(0.0-4.0)^{* *}$ \\
PGA (0-3), median (rank) & $2.8(2.0-3.0)$ & $0.0(0.0-1.0)^{* *}$ & $0.0(0.0-1.0)$ \\
Hospitalization, n (\%) & $25(54 \%)$ & $1(2.3 \%)^{* *}$ & $2(4 \%)^{* *}$ \\
\hline
\end{tabular}

${ }^{* *} p<0,0005$ respect to baseline.

\section{Conclusions}

RTX may be effective in SLE patients refractory to immunosuppressive therapy, as it gets to control disease activity and reduces hospital admissions. For these reasons, RTX should be considered a therapeutic option of first choice in these patients.

\section{Author details}

${ }^{1}$ Rheumatology Unit, Valme University Hospital, Seville, Spain. ${ }^{2}$ Rheumatology Unit, Malaga Civil Hospital, Malaga, Spain. ${ }^{3}$ Rheumatology Unit, Gregorio Marañón University Hospital, Madrid, Spain.

Published: 25 November 2010

doi:10.1186/1479-5876-8-S1-P70

Cite this article as: Martínez-Pérez et al:: Rituximab reduces the

hospitalization in patients with systemic lupus erythematosus. Journal of Translational Medicine 2010 8(Suppl 1):P70.

${ }^{1}$ Rheumatology Unit, Valme University Hospital, Seville, Spain

Full list of author information is available at the end of the article 